\title{
O ICMS-E nos estados da Amazônia: um instrumento de incentivo ao desenvolvimento sustentável?
}

\section{The ICMS-E in the states of the Amazônia: an incentive instrument to sustainable development?}

Maria Rosicleide do Nascimento Araújo - Economista com especialização em Gerenciamento de Projetos Governamentais, Fundação Universidade do Tocantins e Secretaria da Fazenda do Estado do Tocantins, Palmas-TO. E-mail: rosicleidearaujo@uft.edu.br

Mônica Aparecida da Rocha Silva-Socióloga, Doutora em Ciências Sociais. Professora da Universidade Federal do Tocantins (UFTO), atuando junto ao Mestrado em Desenvolvimento Regional. PalmasTO.E-mail: monicars@uft.edu.br

Waldecy Rodrigues - Economista, Pós-Doutorado em Economia pela UnB, 2007. Professor da Universidade Federal do Tocantins (UFTO) atuando no Mestrado em Desenvolvimento Regional. Atualmente é Pró-Reitor de Pesquisa e Pós-Graduação da UFTO, Palmas-TO. E-mail: waldecy@ terra.com.br

\section{Resumo}

A regiãoda Amazônia Legal no Brasil compõese de nove estados, cuja extensão territorial é mais da metade de todo o território nacional, tendo o seu bioma como fundamental para a melhor qualidade de vida no mundo. Este artigo buscou averiguar, dentre os estados que compõem essa região, quais adotaram e implementaram o ICMS-E em suas políticas públicas, e em que medida seus critérios podem ser conceitualmente correlacionados ao desenvolvimento sustentável. Como resultado, verificou-se que dos nove estados da Amazônia Legal, cinco já adotaram esse instrumento baseado no princípio do protetor-beneficiário, apresentando, em sua maioria, incentivo para que seus municípios promovam uma melhor gestão do meio ambiente. Observou-se também que seus critérios são correlacionáveis ao conceito do desenvolvimento sustentável.

\section{Palavras-chave}

CMS Ecológico. Política Pública. Desenvolvimento Sustentável. Princípio do Protetor-Beneficiário.

\begin{abstract}
The Legal Amazon region in Brazil is made up of nine states, whose territorial area is more than half of the entire national territory, taking their biome as fundamental to quality of life in the world. This article sought to determine, among the states that make up this region, which have adopted and implemented the ICMS-E in their public policies, and to what extent their criteria may be conceptually related to sustainable development. As a result it was found that of the nine states of the Legal Amazon, five have adopted this instrument based on the principle of protective payee, featuring mostly incentive for their municipalities promote better management of the environment. It was also observed that your criteria are correlated to the concept of sustainable development.
\end{abstract}

\section{Keywords}

Ecological ICMS. Public Policy. Sustainable Development. The Principle of Protective Payee. 


\section{INTRODUÇÃO}

Esta preocupação com a sustentabilidade do planeta é premente e atual, e ganhou repercussão nos últimos 60 anos. Destaca-se aqui a Conferência Mundial das Nações Unidas sobre o Meio Ambiente e Desenvolvimento (CNUMAD), ocorrida no Rio de Janeiro, em 1992, cujo um dos frutos foi à criação da "Agenda 21". Barbiere (2005) afirma que a Agenda 21 trouxe à tona principalmente a questão do binômio desenvolvimento e meio ambiente sendo visto globalmente, mas tratado localmente, e ainda sustentavelmente. Abordando a questão do desenvolvimento com sustentabilidade, Sachs (2008) afirma que o desenvolvimento sustentável vai além da questão da sustentabilidade ambiental, tendo haver também com a sustentabilidade social.

Neste trabalho, o conceito de desenvolvimento sustentável que teremos como norteador é o apresentado por Sachs (2002), que engloba não só a questão de ações de proteção e conservação do meio ambiente, mas também a necessária participação da população local (autoridades, comunidades e cidadãos) no planejamento destas ações.

Com a reestruturação do Estado e de suas funções no Brasil, ocorrida com a CF/88, outra discussão tomou corpo na década de 1990 - a necessidade de se dividir entre os diversos níveis políticos a responsabilidade de desenvolver o país de forma mais sustentável e com uso de recursos públicos mais otimizados.

Esse novo cenário exigiu um modelo de gestão pública integrado e voltado para a excelência, respeitando as características e particularidades da sociedade em que está inserido. Com isso, as políticas públicas adotadas pelos governos pós-década de 1980, tendem a passar de burocráticas à gerencial, buscando atender a esta nova realidade. Em que pese toda uma discussão sobre política pública que tem ganhado destaque entre os pesquisadores da área, este trabalho não pretende se aprofundar neste item. Mas, apresentar o contexto da política ambiental em que se insere o ICMS- $\mathrm{E}^{1}$, nascido sob a égide do princípio do protetor-beneficiário.

O ICMS-E foi criado no início da década de 1990, implantado primeiramente no estado do Paraná, como uma ferramenta disponível e incentivadora de boas práticas de gestão ambiental para os municípios que o implantar. A sua importância vem do fato de que o mesmo não significa um novo imposto ou maior incremento de tributo, mas é um sistema que vem premiar os municípios que investem em ações ecologicamente corretas e preventivas. Isto se dá através de uma nova repartição dos recursos do Imposto sobre Circulação de

O termo ICMS-E será utilizado neste trabalho como referência para ICMS Ecológico.

Novos Cadernos NAEA, v. 16, n. 1, Suplemento, p. 23-42, jun. 2013 
Mercadorias e Serviços ICMS) arrecadados pelo estado, e que por lei devem ser repassados aos municípios.

A repartição dos recursos arrecadados pelos estados via ICMS, está prevista no art. 158, inciso II, da CF/88, determinando que 25\% dos recursos arrecadados do ICMS pelos estados, serão repassados a seus municípios. Deste percentual que cabe aos municípios, 1/4 deve ser repassado de acordo com as legislações estaduais. É neste percentual de livre gestão estadual que se está inserindo as políticas públicas relativas ao ICMS-E.

Segundo Loureiro (2006), o ICMS-E é formado por um critério ambiental ou conjunto desses critérios, que promove, via repasses de recursos fiscais, a compensação aos municípios que a princípio sofrem restrições de uso de seus territórios, por terem Unidades de Conservação (UC) ou Terras Indígenas (TI). Destaca-se que esta não é uma política obrigatória aos estados, ou seja, cada um a adota e implementa livremente, não havendo por parte do governo federal uma lei que os obrigue. Mas, desde o pioneirismo do estado do Paraná, implementando o ICMS-E no ano de 1991, outros 13 estados já o fizeram (SOUSA; NAKAJIMA; OLIVEIRA, 2011), e conforme diversos pesquisadores que têm estudado sobre o assunto, a experiência desse instrumento de política pública está sendo exitosa para aqueles que o adotam.

Observando-se que todos os estados da Amazônia Legal têm, em maior ou menor extensão, UC e TI em seus territórios, os questionamentos que surgem são: se o ICMS-E está se mostrando uma experiência de êxito na gestão ambiental, principalmente de proteção ao meio ambiente, bem como proporciona outro benefícios às localidades beneficiadas, e se a região amazônica é a maior detentora mundial de biomas essenciais à vida humana, quais estados amazônicos já adotaram essa ferramenta de política pública? E mais, em que medida seus critérios podem ser relacionados com o desenvolvimento sustentável?

Diante desse contexto, este trabalho objetivou pesquisar, dentre os estados que compõem a Amazônia Legal, quais adotaram e implementaram o ICMS-E em suas políticas públicas. Em complementação, buscou-se ainda comparar os critérios adotados por cada estado, identificando suas variáveis específicas e se as mesmas se correlacionam conceitualmente com o desenvolvimento sustentável.

Este trabalho justifica-se pela grande relevância que a região da Amazônia Legal tem para o Brasil e para o mundo, como sustentação da vida, e da necessidade de proteção e conservação de seus biomas, tão amplamente discutidos e conhecido. 


\section{REFERENCIAL TEÓRICO: UMA VISÃO GERAL}

\subsection{PILARES PARA O DESENVOLVIMENTO SUSTENTÁVEL}

Questões sobre a relação existente no tripé homem, meio ambiente e crescimento econômico, têm sido muito discutidas ao longo dos últimos 60 anos, tendo vasta literatura sobre o assunto. Reflexões internacionais sobre os efeitos nocivos desse tripé ao meio ambiente, e a escassez futura dos recursos naturais necessários ao crescimento econômico e a consequente sobrevivência dos seres humanos, iniciaram-se na década de 1960, com a Conferência sobre a Biosfera, em Paris, em 1968. Foladori (2001) afirma que essas discussões se intensificaram nas décadas posteriores, tendo como exemplos notórios: a publicação do livro $O s$ limites do crescimento, pelo Clube de Roma, em 1972; a Declaração de Estocolmo, em 1972, que criou o Programa das Nações Unidas para o Meio Ambiente (PNUMA); e a criação da Comissão de Brundtland, no ano de 1983, que em 1987 divulga o relatório Nosso Futuro Comum.

Este relatório apresentou ao mundo o termo Desenvolvimento Sustentável, sendo entendido como aquele que atende de forma igualitária às necessidades no presente, sem comprometer a capacidade das gerações futuras de satisfazer suas próprias (FOLADORI, 2001). Segundo o referido autor, fica estabelecido que não se deve tratar distinta e separadamente a pobreza, a desigualdade e a degradação ambiental, posto que estas são causa e consequência de sua inter-relação.

Percebe-se que a comunidade internacional passou a tratar como relevante a necessidade de mudanças na forma de produção, buscando uma maneira mais sustentável de crescimento e desenvolvimento que atendesse às necessidades atuais, sem, contudo, comprometer o atendimento das gerações futuras. Conferências sobre o meio ambiente ocorreram e ocorrem desde então, objetivando discutir o tema desenvolvimento com sustentabilidade.

Sobre sustentabilidade, Cavalcanti (1998, p. 165) afirma que esta se refere a "possibilidade de se obterem continuamente condições iguais ou superiores de vida para um grupo de pessoas e seus sucessores em dado ecossistema". O desenvolvimento econômico não significa mais uma alternativa aberta e largamente possível em nível mundial, pois ao ser amplamente aceito o conceito de desenvolvimento sustentável, consequentemente se fixou limites para o progresso material.

A melhoria da qualidade de vida é o que está em jogo na busca pelo desenvolvimento. Ser feliz, ter uma vida longa e plena realização de si mesmo, são os desejos de todo indivíduo, o que pode ser fomentado pelo desenvolvimento,

Novos Cadernos NAEA, v. 16, n. 1, Suplemento, p. 23-42, jun. 2013 
no entanto, isto não significa que para ser feliz as pessoas tenham necessáriamente que ter aumento na posse de bens (CAVALCANTI, 1998).

Esse pensamento é acompanhado por autores que, como Sachs (2008, p. 13), acreditam que "os objetivos do desenvolvimento vão bem além da mera multiplicação da riqueza material. O crescimento é uma condição necessária, mas de forma alguma suficiente [...], para se alcançar a meta de uma vida melhor, mais feliz e mais completa para todos".

Para Sachs (2008), o desenvolvimento sustentável não é só sustentabilidade ambiental, mas também social, e para que este desenvolvimento seja sustentado e sustentável, ele apresenta cinco condições pilares: a) social - a sustentabilidade social vem primeiro por estar intrínseca e instrumentalmente ligada à própria finalidade do desenvolvimento, e pela fragilidade e probabilidade de que haja um colapso social antes mesmo de um ambiental; b) ambiental - a sustentabilidade do meio ambiente, com suas duas dimensões de sustentação da vida e de depósito de resíduos, vem em decorrência da sustentabilidade social; c) territorial relacionada a uma equilibrada distribuição espacial dos recursos, das populações e das atividades; d) econômica - a sustentabilidade econômica é necessária para que as coisas aconteçam, mas não é condição prévia para as anteriores; e e) política - a governança democrática é valor fundamental e instrumento necessário para fazer as coisas acontecerem.

O termo desenvolvimento sustentável vem sendo discutido e estudado ao longo dos últimos anos. No entanto, neste trabalho o conceito que será utilizado é o tratado por Sachs (2002), visto que este envolve tanto a questão de ações de proteção e conservação do meio ambiente, quanto à efetiva participação da população local no planejamento das mesmas.

\subsection{A POLÍTICA PÚBLICA E O PRINCÍPIO DO PROTETOR- BENEFICIÁRIO}

No estudo das questões das políticas públicas, Rua (1998, p. 232) delimita política pública como sendo um "conjunto de procedimentos formais e informais que expressam relações de poder e que se destinam à resolução pacífica dos conflitos quanto a bens públicos".

Saasa (2006), em seu trabalho sobre a formulação da política pública nos países em desenvolvimento, diz que em geral se aceita que a política pública faça parte de um processo consciente de escolha de metas, cujas escolhas estão nas mãos dos agentes deste processo, compreendendo também a identificação das ferramentas para o alcance das metas propostas, e dentro do que os atores são

Novos Cadernos NAEA, v. 16, n. 1, Suplemento, p. 23-42, jun. 2013 
capazes de realizar. As definições dos meios para conseguir alcançar essas metas levam em conta tanto a decisão de fazer quanto de não fazer. O autor afirma ainda que a política deve ser entendida como um "processo social dinâmico" não um ato "isolado e único" (SAASA,2006, p. 219).

Souza (2006, p. 37), ao analisar as variadas definições de políticas públicas, as sintetizas em seis elementos fundamentais, que permitem: a) distinção entre o que o governo pretende fazer e o que, de fato, faz; b) envolvimento de diversos stakeholders (pessoas envolvidas) e níveis de decisão, materializados pelos governos com participantes formais e informais; c) abrangência generalizada não se limitando às leis e regras; d) ação propositada, tendo objetivos específicos a serem alcançados; e) ter impactos no curto, com políticas de longo prazo; e f) envolve processos subsequentes após sua decisão e proposição, ou seja, provoca também implementação, execução e avaliação.

As políticas públicas envolvem decisões e ações de governo e de outros atores sociais, e engloba tudo que diz respeito à vida coletiva das pessoas, tanto em sociedade quanto em suas organizações. Assim, segundo Heidemann (2009, p. 28), o homem é um ser político por natureza, e a "política é também a arte de governar e realizar o bem público", que é representado pelo desenvolvimento. Operacionalmente, segundo o autor, "a política é entendida como ações, práticas, diretrizes políticas, fundadas em leis e empreendidas como funções do Estado por um governo, para resolver questões gerais e específicas da sociedade” (Ibid, p. 29).

Heidemann (2009) afirma que atualmente a sociedade brasileira deve preocupar-se com a instituição governo, por três motivos principais: primeiro pela necessidade de um governo societário que regule politicamente seu sistema de mercado; segundo. Porque esse governo societário deve preocupar-se em atender à crescente demanda da sociedade por uma educação democrática, pela proteção ao patrimônio natural, pela função social do capital econômico, pela defesa da dignidade humana e por combater as desigualdades socioeconômicas. Em terceiro lugar, tem a questão fiscal, pela qual é buscada a eficiência do esforço do governo, isto é, uma melhor e mais otimizada alocação dos recursos públicos oriundos dos tributos pagos pela sociedade, o que o autor denomina de administração pública gerencial.

Não se pretende, neste trabalho, entrar na seara das políticas públicas quanto ao seu desenho e regras, ou mesmo às questões que envolvem sua decisão, elaboração, implementação, monitoramento ou avaliação. Neste sentido, simplificadamente, as políticas públicas podem ser consideradas como ações de um governo, no intuito de resolver conflitos da sociedade em relação aos bens públicos.

Novos Cadernos NAEA, v. 16, n. 1, Suplemento, p. 23-42, jun. 2013 
Considerando o tema da gestão ambiental e desenvolvimento sustentável, discutido anteriormente, como sendo uma questão relativa a bens públicos afetos a toda a sociedade, e que estes devem ter a ação do Estado, inserem-se as políticas públicas de incentivo à proteção ao meio ambiente como a do ICMS-E, criada sob a égide do princípio do protetor-beneficiário.

Em contraponto ao princípio do poluidor-pagador que, grosso modo, significa dizer que cabe ao poluidor arcar com os custos de recuperação do meio ambiente afetado por suas ações, surge o princípio do protetor-recebedor ou protetor-beneficiário. De acordo com Ribeiro (1998), o agente público ou privado que de alguma forma protege um bem natural que reverta em benefício da comunidade, deve receber uma compensação financeira como incentivo pelo serviço prestado.

Para Ribeiro (1998), o princípio do protetor-beneficiário serve de incentivo econômico a quem protege áreas como as $\mathrm{UC}^{2}$, que são sujeitas a regras e normas legais específicas de uso, nos três níveis de governo (federal, estadual e municipal), e representa um símbolo de justiça econômica, no momento que valoriza os serviços ambientais prestados, remunerando esse serviço, partindo do pressuposto que, se tem valor econômico, é justo que se receba por ele.

Sobre o ICMS-E, Loureiro (2006) afirma que no estado do Paraná a sua implantação foi motivada pela mobilização política dos municípios, associada à necessidade de modernizar as políticas públicas ambientais, e que isto ocorreu em virtude desses municípios se considerarem "penalizados por terem parte do seu território (ou a totalidade) restrito ao uso por representarem mananciais de abastecimento público para municípios vizinhos ou ainda por possuírem Unidades de Conservação" (Ibid, p. 3).

$\mathrm{Na}$ mesma linha de entendimento, Sousa, Nakajima e Oliveira (2011) dizem que o objetivo do ICMS-E é propiciar aos municípios que têm algum tipo de restrição de uso territorial, a compensação financeira pela forçosa restrição em virtude da necessidade de conservação e preservação de áreas legalmente protegidas. Os referidos autores (2011) creditam a criação desse instrumento de política pública à busca de um modelo de gestão ambiental que seja eficiente, que atenda às especificidades de cada região e, ainda, que incentive a manutenção e preservação do meio ambiente.

2 As unidades de conservação (UC) são espaços territoriais, incluindo seus recursos ambientais, com características naturais relevantes, que têm a função de assegurar a representatividade de amostras significativas e ecologicamente viáveis das diferentes populações, hábitat e ecossistemas do território nacional e das águas jurisdicionais, preservando o patrimônio biológico existente. São elas: Estação Ecológica, Reserva Biológica, Parque, Monumento Natural, Área de Proteção Ambiental, Reserva Indígena, Floresta, entre ouras (MMA, 2012).

Novos Cadernos NAEA, v. 16, n. 1, Suplemento, p. 23-42, jun. 2013 
Como resultado de seus estudos, Sousa, Nakajima e Oliveira (2011) destacam que este instrumento é "uma medida positiva que está conscientizando as populações sobre a importância da conservação ambiental” e, ainda, que está sendo implementado respeitando as prioridades ambientais e até mesmo sociais da cada estado da Federação, como, por exemplo: a criação e manutenção de UC, ação de saneamento básico e investimentos em educação e saúde (2011).

Ribeiro (1998), Loureiro (2006) e Sousa; Nakajima e Oliveira (2011) concluem que o ICMS-E é um instrumento de grande impacto para o fomento, conservação e proteção de áreas protegidas, ocasionando, por exemplo, um aumento na quantidade de UC municipais no estado do Paraná, que de 1991 a 2005 cresceu mais de $2.580 \%$ (LOUREIRO, 2006).

No seminário "Instrumentos Econômicos para o Desenvolvimento Sustentável da Amazônia”, promovido pelo Ministério do Meio Ambiente, em 2002, já se discutia o ICMS-E como um instrumento de compensação fiscal e incentivador de proteção ambiental. Segundo May:

No ICMS-Ecológico, a definição de um gabarito vertical, premiando melhorias na qualidade da gestão das áreas protegidas, servindo de gatilho para incremento na fórmula de alocação de receita, é recomendada como instrumento de incentivo para aprimoramento das ações locais (MAY, 2005, p. 122).

Uma melhoria qualitativa na gestão ambiental municipal leva, a princípio, a um aumento dos recursos recebidos via ICMS-E, o que propicia um círculo virtuoso para os municípios que promoverem essas benfeitorias. No entanto, Loureiro (2006) faz algumas recomendações para o seu aperfeiçoamento, como: a necessidade de ampliação e otimização do ICMS-E nos estados que já o possuem, acrescentando critérios socioambientais (saneamento básico, tratamento do lixo, entre outros); o necessário fortalecimento permanente dos programas estaduais de UC. Para haver a consolidação dessa política pública, deve-se tratar da questão da afetação da receita municipal advinda do ICMS-E ou por vias de um carimbo ambiental a estes recursos ou pela efetiva participação da sociedade na gestão dos gastos públicos.

\section{METODOLOGIA}

As metodologias utilizadas neste trabalho foram: exploratória, descritiva e explicativa (ANDRADE, 2010). Sendo o seguinte: a exploratória foi realizada através da revisão da literatura, com uma pesquisa bibliográfica abordando 
autores e pesquisadores que já efetuaram estudos, e desenvolveram teorias e conceitos sobre os assuntos em questão, referenciando-os e citando-os, de forma a aumentar a compreensão sobre os mesmo. A pesquisa descritiva buscou estabelecer as relações entre o ICMS-E adotado nos estados da Amazônia Legal e as teorias de desenvolvimento sustentável, e a pesquisa explicativa procurou mostrar os fatores contributivos da política pública do ICMS-E como indutora das boas práticas de gestão ambiental nos municípios. Para este trabalho, além da pesquisa bibliográfica e documental, efetuou-se a coleta de dados em fontes secundárias, com busca em meios eletrônicos em sites oficiais dos estados da região Amazônica, além de sites de organizações governamentais e de não governamentais.

Algumas limitações foram percebidas, como a falta da disponibilidade de dados por parte de alguns estados, bem como a dificuldade de se verificar com clareza as alterações, revogações e outros meios legais que sofreram as leis e decretos de regulamentação do assunto. Os estados que não estão com o seu processo de implantação do ICMS-E foram apenas referenciados, não sendo possível fazer uma análise mais apurada.

\section{RESULTADOS: O ICMS ECOLÓGICO NOS ESTADOS DA AMAZÔNIA LEGAL}

Conforme a pesquisa, a região da Amazônia Legal compõe-se de nove estados (Figura 1), e os resultados dos dados pesquisados sobre o ICMS-E, demonstraram que dos nove, cinco já adotaram essa ferramenta de política pública, três estão com projetos de leis em tramitação e um ainda não possui propostas sobre o tema.

Mas, antes dessa análise específica, cabe uma breve apresentação relativa às UC e às TI que serão consideradas neste trabalho, aquelas demarcadas pela União Federal, conforme o Quadro 1. Os estados e municípios também têm UC $^{3}$, sendo o principal intuito do ICMS-E, a compensação aos municípios pela restrição de uso dessas unidades, além de conservar as já existentes, incentivar também a criação de novas áreas de proteção ambiental. No entanto, focaram-se, neste trabalho, as áreas demarcadas no âmbito federal.

\footnotetext{
Para mais informações sobre Unidades de Conservação (UC), consultar: http://www.mma. gov.br/areas-protegidas/sistema-nacional-de-ucs-snuc.
}

Novos Cadernos NAEA, v. 16, n. 1, Suplemento, p. 23-42, jun. 2013 
Figura 1 - Estados da Amazônia Legal.

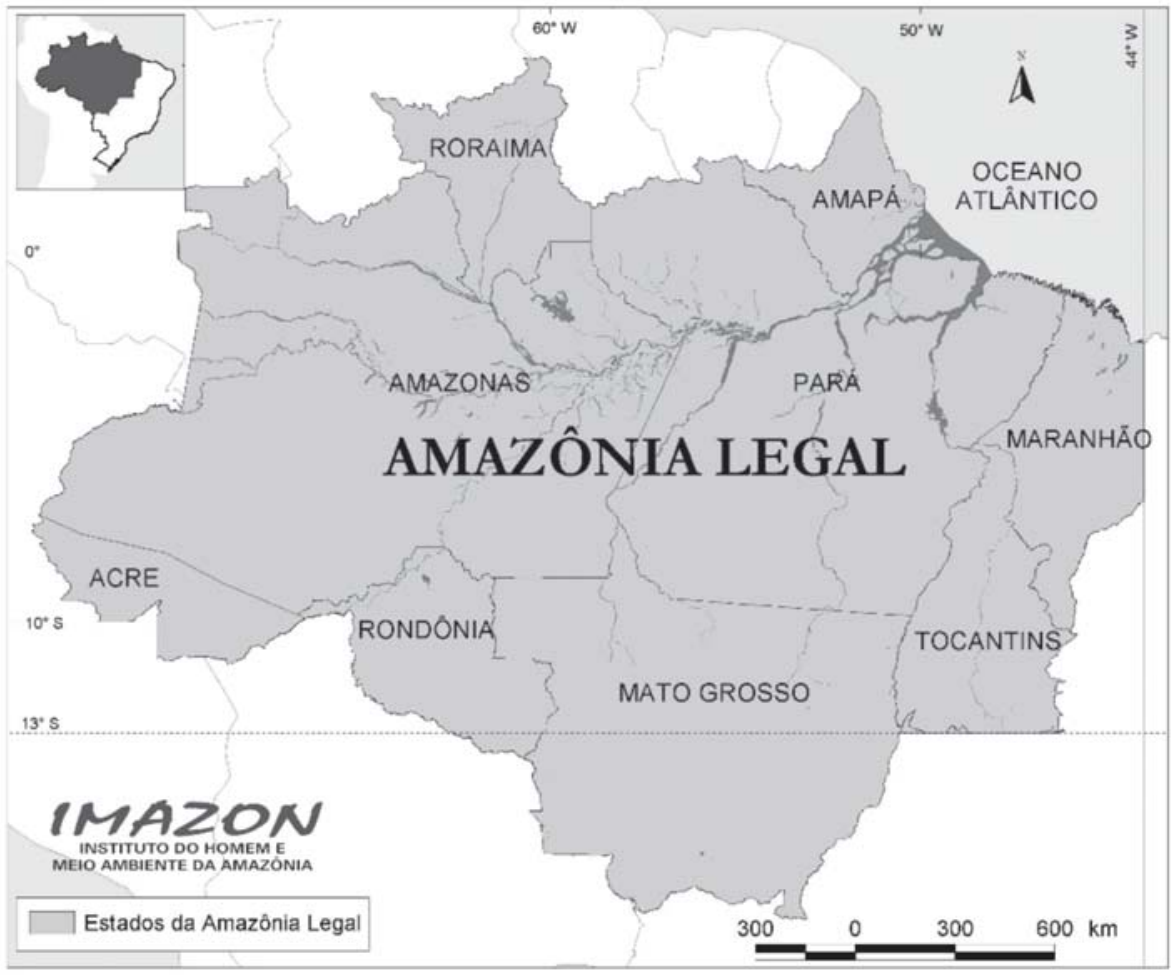

Fonte: IMAZON - Instituto do Home e Meio Ambiente da Amazônia.

Quadro 1 - Unidades de conservação federais e terras indígenas demarcadas e respectivas áreas por unidade da Federação - estados da região da Amazônia Legal.

\begin{tabular}{|l|c|}
\hline \multicolumn{1}{|c|}{ Estado } & UC e TI em $\%$ do território total \\
\hline Roraima & 49,75 \\
\hline Rondônia & 30,12 \\
\hline Amazonas & 25,84 \\
\hline Acre & 25,20 \\
\hline Mato Grosso & 13,54 \\
\hline Amapá & 12,53 \\
\hline Pará & 12,53 \\
\hline Tocantins & 9,20 \\
\hline Maranhão & 6,50 \\
\hline
\end{tabular}

Fonte: Ministério do Meio Ambiente - MMA (2012). Elaboração dos autores.

Os estados serão apresentados nos próximos tópicos, pela ordem de data das respectivas leis de instituição do ICMS-E.

Novos Cadernos NAEA, v. 16, n. 1, Suplemento, p. 23-42, jun. 2013 


\subsection{ESTADO DE RONDÔNIA}

O ICMS Ecológico foi instituído no estado de Rondônia através da Lei Complementar n. 147, de janeiro de 1996, mas só foi regulamentado em dezembro de 2001, pelo Decreto n. 9.787, que foi posteriormente substituído pelo Decreto n. 11.908, de dezembro de 2005, que assim determina no Artigo $3^{\circ}, \mathrm{V}, \int 2$ :

O valor destinado ao município em decorrência de sua participação no produto da arrecadação do ICMS será determinado segundo os seguintes critérios:

$[\cdots]$

$\mathrm{V}-5 \%$ (cinco por cento) proporcionais à ocupação territorial dos municípios com unidades de conservação, considerando a relação entre a área total, em quilômetros quadrados, das unidades de conservação do município e a área total das unidades de conservação do estado no ano imediatamente anterior ao da apuração dos índices.

$[\ldots]$

$\int 2^{\circ}$ Compreendem as unidades de conservação as áreas protegidas e estabelecidas em ecossistemas significativos do território estadual no âmbito administrativo do Governo Federal, Estadual ou Municipal, nas categorias de Estação Ecológica, Reserva Biológica, Parque, Monumento Natural, Área de Proteção Ambiental, Reserva Indígena, Floresta, Reserva Extrativista e outras incluídas em quaisquer categorias de unidade de conservação, criadas por lei ou decreto municipal, estadual ou federal.

O estado de Rondônia, em sua legislação, determina uma redução nos cálculos de repasses aos municípios em que comprovadamente ocorrerem invasões de terra ou explorações ilegais. Neste caso, os valores serão repartidos entre os outros municípios que estiverem promovendo uma melhor gestão ambiental de suas UC. Considerando que este estado, segundo dados do Ministério do Meio Ambiente (MMA), tem cerca de 30\% de seu território ocupado por UC/TI, o caráter compensatório do ICMS-E é altamente relevante. Veja-se aqui que os princípios do protetor beneficiário, sendo beneficiado com um maior valor de repasse, aquele que tiver boas práticas de gestão ambiental municipal.

\subsection{ESTADO DO AMAPÁ}

O estado do Amapá adotou o ICMS-E no ano de 1996, pela Lei n. 322, que estabeleceu em 1,4\% o percentual do ICMS arrecadado, na composição do 
critério ambiental. O Amapá é um caso atípico, do ponto de vista legal, pois a regulamentação dos critérios de repasse do ICMS está contida no Anexo Único à própria lei. É o $\int 7$ deste, anexo que traz o Índice de Conservação do Município (ICM), tendo como único fator de composição as UC.

O Amapá implantou o ICMS-E gradualmente, de 1998 até 2002, partindo de pouco mais de $1,13 \%$ até chegar a $1,4 \%$, fator que prevalece até o momento. Essa implantação gradual permite aos municípios impactados se adaptarem, e segundo Simioni (2009, p. 55), “diminui os impactos adversos e prejudiciais aos municípios, possibilitando a adaptação dos mesmos frente aos percentuais praticados, principalmente aqueles que sofrem a redução do repasse de recursos". O estado contempla, na análise dos índices do ICMS-E, tanto variáveis quantitativas quanto qualitativas na avaliação das UC para os cálculos do ICM, que considera o Fator de Conservação para Categorias de Manejo de Unidades de Conservação. Com relação ao percentual de território que tem restrição de uso, no Amapá este corresponde a 12,53\% do total de sua área territorial.

\subsection{ESTADO DO MATO GROSSO}

O ICMS-E no estado do Mato Grosso foi criado no ano de 2000, pela Lei Complementar n. 73, e regulamentado em 2001, com o Decreto Estadual n. 2.758, sendo que sua implementação ocorreu ano de 2002. Os critérios adotados pelo estado inicialmente eram focados nas UC e TI. Houve algumas alterações na legislação do ICMS-E, e atualmente predomina os critérios de UC e TI, sendo o embasamento legal a Lei Complementar n. 157, de janeiro de 2004, e a Instrução Normativa $n^{\circ} 1$, de maio de 2010. A primeira estabeleceu as normas referentes ao cálculo dos Índices de Participação dos Municípios do Estado do Mato Grosso (IPM/ICMS), a segunda regulou os procedimentos administrativos para organização do Cadastro Estadual de Unidades de Conservação e Terras Indígenas, a operacionalização dos cálculos e gestão do Programa do ICMS-E, a publicação e democratização das informações, e outras providências. O percentual de repasse relativo ao ICMS-E mato-grossense permaneceu o que estava determinado no art. $2^{\circ}$ da Lei Complementar n. 157/2004, que determina:

Art. $2^{\circ}$ Os Índices de Participação dos Municípios no produto da arrecadação do ICMS serão apurados com observância dos critérios abaixo relacionados:

$[\ldots]$

VI - unidade de conservação/terra indígena: 5\% (cinco por cento) através da relação percentual entre o índice de unidade de conservação/terra

Novos Cadernos NAEA, v. 16, n. 1, Suplemento, p. 23-42, jun. 2013 
indígena do Município e a soma dos índices de unidades de conservação/ terra indígena de todos os Municípios do Estado, apurados pela Fundação Estadual do Meio Ambiente - FEMA.

Do território total de Mato Grosso, 13,54\% refere-se à UC/TI federais. Mas observa-se que a Instrução Normativa - IN 01/2010 traz, além de variável quantitativa, a preocupação com a qualidade, visto que:

$\int 1^{\circ}$ As Unidades de Conservação para as quais se exige dominialidade pública, têm como requisito para sua inclusão no Cadastro, o seu efetivo Planejamento, Implementação e Manutenção, inclusive quanto à regularização fundiária, bem como a sua efetiva apropriação social.

Por apropriação social, a IN 01/2010 considera no \ 3º "o nível de legitimidade social alcançada pelas Unidades de Conservação diante de seus demandadores, o que pode ser caracterizado, dentre outras, por ações compatíveis com seus objetivos, e respectivas Categorias de Manejo". Como categorias de manejo das UC, sinteticamente têm-se: democratização de informações, educação ambiental, regulamentação; ecoturismo e ações similares; produção de baixo impacto; e pesquisa, estudos. Fica claro aqui, que os municípios que promoverem boas práticas de gestão ambiental, receberão maior fatia dos repasses do ICMS-E.

\subsection{ESTADO DO TOCANTINS}

O estado do Tocantins adotou o ICMS-E em 2002 através da Lei n. 1.323, que já em seu primeiro artigo diz:

Art. 1o Na composição dos cálculos da parcela do produto da arrecadação do Imposto Sobre Operações Relativas à Circulação de Mercadorias e sobre a Prestação de Serviços de Transporte Interestadual e Intermunicipal e de Comunicação - ICMS, a partir do exercício de 2003, serão adotados índices que incentivem os municípios a:

I - criar leis, decretos e dotações orçamentárias que resultem na estruturação e implementação da Política Municipal de Meio Ambiente e da Agenda 21 local;

II - abrigar unidades de conservação ambiental, inclusive terras Indígenas; III - controlar queimadas e combater incêndios;

IV - promover:

a) a conservação e o manejo do solo;

b) o saneamento básico;

c) a conservação da água;

d) a coleta e destinação do lixo.

Novos Cadernos NAEA, v. 16, n. 1, Suplemento, p. 23-42, jun. 2013 
Sua implantação foi gradativa, iniciando no ano de 2003 com 3,5\% e chegando a 13\% em 2007. Este é o maior percentual de repasse entre os estados da Amazônia Legal. Como visto, além das UC e das TI (Quadro 1), que representam 9,2\% do total do seu território, o Tocantins adotou outros critérios para o repasse do ICMS-E: a criação de políticas municipais de meio ambiente; o controle de queimadas e combate a incêndios; a conservação do solo; e o saneamento básico, conservação da água, coleta e destinação do lixo. Cada um desses critérios tem variáveis quantitativas e qualitativas, por exemplo, o critério da política municipal de meio ambiente, tem como indicadores:

a) qualitativo, a elaboração legislativa e o cumprimento da legislação específica;

b) quantitativo, a dotação orçamentária realizada;

A legislação tocantinense do ICMS-E determina ainda que deverão ser considerados nos cálculos dos indicadores: a) participação pública no planejamento e gestão das ações; b) avaliação da qualidade; c) educação ambiental; d) desenvolvimento do ecoturismo, quando for o caso; e) aplicação dos recursos repassados ao município em matérias de meio ambiente . Verificase que os critérios de ICMS-E tocantinense estão pautados pela prática da boa gestão ambiental municipal, para beneficiar e recompensar os municípios que melhor gerirem seus recursos ambientais.

\subsection{ESTADO DO ACRE}

No Acre, o repasse do ICMS-E, ou melhor, ICMS Verde para os municípios, está determinado em 5\% do percentual do ICMS arrecadado pelo estado. O Decreto n. 4.918, de dezembro de 2009, regulamentou a Lei n. 1.530, de janeiro de 2004, que definiu o percentual de ICMS-E para ser repassado aos municípios que promovessem práticas de conservação da biodiversidade e executassem projetos de desenvolvimento sustentável, saúde e educação. Sua implantação está

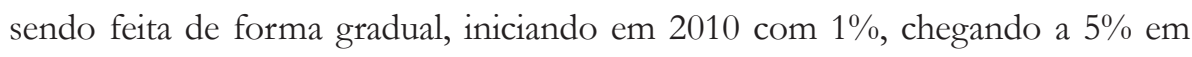
2014. As UC consideradas no caso do ICMS-E acriano, serão as previstas no Sistema Nacional de Unidades de Conservação da Natureza (SNUC) e/ou no Sistema Estadual de Áreas Naturais Protegidas (SEANP) e as Terras Indígenas. O percentual do território do Acre, que tem UC/TI federais corresponde a 25,20\% do total, logo a restrição de uso refere-se a quase um terço de seus domínios.

Novos Cadernos NAEA, v. 16, n. 1, Suplemento, p. 23-42, jun. 2013 
O estado do Acre, no Decreto n ${ }^{\circ}$ 4.918/2009, o art. $2^{\circ}$, determina que para se beneficiar dos recursos previstos na Lei no 1.530 , de 2004, cada município deverá organizar, obrigatoriamente, seu próprio Sistema Municipal de Meio Ambiente, composto, no mínimo, por: I - Conselho Municipal de Meio Ambiente, deliberativo e paritário; II - Fundo Municipal de Meio Ambiente, gerido pelo Conselho; e III - órgão administrativo executor da política ambiental municipal, dotado de recursos humanos, materiais e financeiros adequados e suficientes para exercer suas funções, em especial a implantação da Agenda 21 local. Ao determinar que os gestores municipais criem e organizem seus sistemas próprios de meio ambiente, o estado do Acre busca incentivar a estes promoverem e executarem práticas de gestão ambientais consideradas positivas.

Verifica-se até o momento que dos nove estados da região da Amazônia Legal, cinco já adotaram o ICMS-E, ou ICMS Verde, no caso do estado Acre, conforme pode ser visto no Quadro 2, que traz de forma sintética os estados, as leis de criação e o ano, o percentual de repasse total, bem como os critérios adotados e os percentuais específicos de cada um. Na totalidade, o critério de UC e TI é utilizado por todos, sendo que o estado do Tocantins acrescentou a estes, outros critérios considerados como socioambientais.

Os estados da região Amazônica que ainda não adotaram o ICMS-E, são: Amazonas, Maranhão, Pará e Roraima. Os três primeiros têm debatido a adoção desse instrumento de política pública, sendo que o estado do Pará já tem projeto de lei tramitando na Assembleia Legislativa, cuja aplicação, como em outros estados, está prevista para ser de forma gradual, indo de $2 \%$ em 2012, para 8\% em 2015, também terá as UC como foco principal.

O estado de Roraima é o único para o qual não foram observadas quaisquer informações acerca do ICMS-E como possível ferramenta indutora de proteção e conservação de seus recursos naturais. No entanto, observa-se no Quadro 1, que este possui o maior percentual de UC/TI federais, que é de 49,75\% do total do seu território. Os estados do Amazonas, Maranhão e Pará têm, respectivamente, $25,84 \%, 6,50 \%$ e $12,53 \%$ de áreas protegidas por lei. Isto representa, de alguma forma, uma maior ou menor restrição de uso de seus domínios, que poderia ser minimizada com a adoção dessa ferramenta como política pública compensatória, baseada no princípio do protetor-beneficiário. 
Quadro 2 - Resumo sintético dos estados da região da Amazônia Legal que têm o ICMS-E/ICMS Verde.

\begin{tabular}{|c|c|c|c|c|}
\hline \multirow[t]{2}{*}{ Estado } & \multirow{2}{*}{$\begin{array}{c}\text { Lei de } \\
\text { criação/ano }\end{array}$} & \multirow{2}{*}{$\begin{array}{l}\text { Percentual } \\
\text { de repasse } \\
\text { total }(\%)\end{array}$} & \multicolumn{2}{|l|}{$\begin{array}{l}\text { Critérios e percentual do ICMS } \\
\text { Ecológico }\end{array}$} \\
\hline & & & Critérios & $\%$ \\
\hline Rondônia & $\begin{array}{l}\text { Lei } \\
\text { Complementar } \\
\text { N. }{ }^{\circ} 147 / 96 \\
\end{array}$ & 5 & $\begin{array}{l}\text { Unidade de conservação federal, } \\
\text { estadual ou municipal e terras } \\
\text { indígenas. }\end{array}$ & 5 \\
\hline Amapá & $\begin{array}{l}\text { Lei Estadual } \\
\text { N. } 322 / 96\end{array}$ & 1,4 & $\begin{array}{l}\text { Índice de Conservação do } \\
\text { Município - baseado nas } \\
\text { unidades de conservação } \\
\text { estaduais, municipais ou federais e } \\
\text { particulares. }\end{array}$ & 1,4 \\
\hline $\begin{array}{l}\text { Mato } \\
\text { Grosso }\end{array}$ & $\begin{array}{l}\text { Lei } \\
\text { Complementar } \\
\text { N. }{ }^{\circ} 73 / 00 \\
\end{array}$ & 5 & $\begin{array}{l}\text { Unidades de conservação e terras } \\
\text { indígenas. }\end{array}$ & 5 \\
\hline \multirow{5}{*}{ Tocantins } & \multirow{5}{*}{$\begin{array}{l}\text { Lei Estadual } \\
\text { N. }{ }^{\circ} 1.323 / 02\end{array}$} & \multirow{5}{*}{13} & $\begin{array}{l}\text { Política Municipal de Meio } \\
\text { Ambiente. }\end{array}$ & 2 \\
\hline & & & $\begin{array}{l}\text { Unidades de conservação e terras } \\
\text { indígenas. }\end{array}$ & 3,5 \\
\hline & & & $\begin{array}{l}\text { Controle de queimadas e combate } \\
\text { a incêndios. }\end{array}$ & 2 \\
\hline & & & Conservação dos solos. & 2 \\
\hline & & & $\begin{array}{l}\text { Saneamento básico e conservação } \\
\text { da água. }\end{array}$ & 3,5 \\
\hline $\begin{array}{l}\text { Acre } \\
\text { ICMS } \\
\text { Verde }\end{array}$ & $\begin{array}{l}\text { Lei Estadual } \\
\text { N.o } 1.530 / 04\end{array}$ & 5 & $\begin{array}{l}\text { Unidades de conservação e áreas } \\
\text { afetadas por elas (entorno). }\end{array}$ & 5 \\
\hline
\end{tabular}

Fonte: Legislações estaduais/Elaboração dos autores.

\section{CONSIDERAÇÕES FINAIS}

Como resultado da pesquisa, e respondendo aos questionamentos feitos inicialmente, verificou-se, neste trabalho, que dos nove estados da Amazônia Legal, cinco já adotaram o ICMS-E, sendo eles: Rondônia, Amapá, Mato Grosso, Tocantins e Acre; e três estão discutindo o assunto, que são: Amazonas, Maranhão, Pará, e apenas o estado de Roraima ainda não abordou o tema. Curiosamente é o que tem quase 50\% de seu território com restrição de uso em virtude das UC. Os critérios, de conservação e proteção das UC foram adotados por todos os estados da região da Amazônia Legal que implantaram a política pública do ICMS-E, sendo que o Tocantins inovou e acrescentou outros critérios como: criação e implementação de políticas de meio ambiente municipais, ações

Novos Cadernos NAEA, v. 16, n. 1, Suplemento, p. 23-42, jun. 2013 
municipais de controle e combate às queimadas, de conservação dos solos, de saneamento básico e de conservação das águas. Na grande maioria, os estados também adotaram variáveis qualitativas e quantitativas para os cálculos dos valores de repasse do ICMS-E aos municípios.

Percebe-se uma correlação entre os critérios e as variáveis do ICMS-E e o conceito de desenvolvimento sustentável, baseada nos pilares: social, ambiental, territorial, econômico e político. Tendo em vista que a conservação da biodiversidade é condição imprescindível para que o desenvolvimento aconteça de forma sustentável, e que esta está totalmente inserida nos critérios do ICMS-E, vide proteção e conservação da UC, tanto de forma quantitativa quanto qualitativamente, conclui-se que há uma relação entre eles. No tocante à sustentabilidade territorial e econômica, estas podem ser percebidas na medida em que, via recebimento de recursos como compensação financeira pela limitação ao uso de seus territórios que têm áreas protegidas, os municípios que até então não podiam fazer uso de sua totalidade territorial, e com isso não podiam auferir recursos financeiros sobre estas áreas, têm nos repasses do ICMS-E uma recompensa por essa restrição e um incentivo para melhoria na gestão ambiental municipal, já que isto pode reverter em aumento de arrecadação.

$\mathrm{Na}$ questão da sustentabilidade política e social, percebe-se uma tênue relação através do incentivo a que a governança democrática aconteça, com a indução da participação da sociedade local na tomada de decisão quanto ao planejamento, gestão e avaliação das ações a que o ICMS-E se refere. Este é considerado também como um modelo de gestão ambiental eficiente, e importante ferramenta de conscientização da preservação do meio ambiente por parte da sociedade local.

Por si só, o ICMS-E, como instrumento único de política pública ambiental, não deve ser considerado como o "salvador da pátria", embora consiga solucionar relevantes problemas de meio ambiente. Porém, fica evidente o caráter indutor das boas práticas de gestão ambiental que esse instrumento tem, em nível local, tanto pelos gestores municipais, quanto pela sociedade, que pode e deve participar das decisões que envolvem a priori a possibilidade de uma melhor qualidade de vida, o que leva a um desenvolvimento sustentável.

\section{REFERÊNCIAS}

ACRE. Lei Estadual n ${ }^{\circ}$ 1.530, de 22 de janeiro de 2004. Institui o ICMS Verde, destinando cinco por cento da arrecadação deste tributo para os municípios com unidades de conservação ambiental. Diário Oficial do Estado do Acre. Disponível em: <http://www.ccjr.ac.gov.br/leisordinarias/2004/Lei1530.doc>. Acesso em: 01 jul. 2012. 
AMAPÁ. Lei Estadual no 322, de 23 de dezembro de 1996. Dispõe sobre a distribuição da parcela da receita do produto da arrecadação dos impostos estaduais conforme disposições contidas no artigo 158 da Constituição Federal e Lei Complementar Federal n. 63/90, e dá outras providências. Diário Oficial do Estado do Amapá, n. 1469, de 23 dez. 1996. Disponível em: <http:/ /www. al.ap.gov.br/leiord4.htm>. Acesso em: 01 jul. 2012.

AMAZONAS. Disponível em: <http://www.amazonas.am.gov.br/> Acesso em: 01 jul. 2012.

ANDRADE, M. M. de. Introdução à metodologia do trabalho: elaboração de trabalhos na graduação. 10. ed. São Paulo: Atlas, 2010.

ASSOCIAÇÃO BRASILEIRA DE NORMAS TÉCNICAS. NBR6023: informação e documentos - referências e elaboração. Rio de Janeiro: ABNT, 2002.

BARBIERI, J. C. Desenvolvimento e meio ambiente: as estratégias de mudanças da Agenda 21. 7. ed. Petrópolis: Vozes, 2005.

CAVALCANTI, C. (Org.). Desenvolvimento e natureza: estudo de uma sociedade sustentável. 2. ed. São Paulo: Cortez; Recife: Fundação Joaquim Nabuco, 1998.

DINIZ, N. S. M. FPE Verde: uma fonte para o desenvolvimento sustentável. In: MAY, P. H. et al. Instrumentos econômicos para o desenvolvimento sustentável na Amazônia brasileira. Brasília: Ministério do Meio Ambiente, 2005. p. 83-90.

FOLADORI, G. Limites do desenvolvimento sustentável. Tradução Marise Manoel. Campinas: Unicamp; São Paulo: Imprensa Oficial, 2001.

HEIDEMANN, F. G. Do sonho do progresso às políticas de desenvolvimento. In: SALM, J. F. (Org.). Políticas públicas e desenvolvimento: bases epistemológicas e modelos de análise. 2. ed. Brasília: UNB, 2009. p. 23-40.

IBGE. Geoestatísticas de Recursos Naturais da Amazônia Legal. 2011. Disponível em: <http://www.ibge.gov.br/home/presidencia/noticias/noticia_ visualiza.php?id_noticia=1887\&id_pagina=1> Acesso em: 1 jul. 2012.

IMAZON-Instituto do Homem e do Meio ambiente da Amazônia. Mapa Estados da Amazônia Legal. Disponível em: <http://www.imazon.org.br/ mapas/amazonia-legal/mage_view_fullscreen.> Acesso em: 2 jul. 2012.

LOUREIRO, W. O ICMS ecológico, um instrumento econômico de gestão ambiental aplicado aos municípios. In: ENCONTRO NACIONAL DA ANNAMA, 16. 2006, Blumenau. Anais... 2006. Disponível em: <http://www. icmsecologico.org.br/images/artigos >. Acesso em 20 abr. 2012.

Novos Cadernos NAEA, v. 16, n. 1, Suplemento, p. 23-42, jun. 2013 
O ICMS Ecológico na Biodiversidade. Curitiba, 2000.

MMA-Ministério do Meio Ambiente. Áreas protegidas. Disponível em: <www. mma.gov.br> Acesso em: 1 jul. 2012.

MAY, P. H. et. al. Instrumentos econômicos para o desenvolvimento sustentável na Amazônia brasileira. Brasília: Ministério do Meio Ambiente, 2005.

MARANHÃO. Disponível em: <http://www.ma.gov.br/> Acesso em: 1 jul.2012.

MATO GROSSO. Secretaria de Estado do Meio Ambiente. Superintendência de Biodiversidade. Coordenadoria de Unidades de Conservação. ICMS Ecológico: conservando a biodiversidade mato-grossense. Cuiabá, 2009. Disponível em: $<$ http://www.icmsecologico.org.br/images/ legislacao/leg054. pdf> Acesso em: 2 jul. 2012.

PARÁ. Disponível em: <http://www.pa.gov.br/> Acesso em: 1 jul. 2012.

RIBEIRO, M. A. O Princípio Protetor Recebedor para preservar um bem natural. Revista Eco 21, Rio de Janeiro, 1998. Disponível em: <www.ida.org. br/ARTIGOS/ principioproteotr.html>. Acesso em 20 abr. 2012.

RONDÔNIA. Lei Complementar n ${ }^{\circ}$. 147, de 15 de janeiro de 1996. Altera e acrescenta dispositivos à Lei Complementar $\mathrm{n}^{\circ} 115$, de 14 de junho de 1994, e dá outras providências. Diário Oficial do Estado de Rondônia, n. 3428, de 15 de janeiro de 1996. Disponível em: <www.portal.sefin.ro.gov.br/site/arquivos/ anexos/52.31394529513822LC96-147- LT.20LC115.PDF>. Acesso em: 1 jul. 2012.

RORAIMA. Disponível em: <http://www.rr.gov.br/> Acesso em: 1 jul. 2012.

RUA, M. G. Análise de Políticas: conceitos básicos. In: CARVALHO, M. I. V. (Org.). O estudo da política: tópicos selecionados. Brasília: Paralelo 15, 1998.

SAASA, O. A formulação da política pública nos países em desenvolvimento: a utilidade dos modelos contemporâneos de tomada de decisão. In: SARAVIA, R.; FERRAREZI, E. (Org.). Políticas públicas. Brasilia: ENAP, 2006. v. 2. 5, p. 219-238.

SACHS, I.; STROCH. P. Y. (Org.). Caminhos para o desenvolvimento sustentável. Rio de Janeiro: Garamond, 2002.

Desenvolvimento includente, sustentável e sustentado. Rio de Janeiro: Garamond, 2008. 
SIMIONI, M. de P. ICMS Ecológico e terras indígenas: um estudo de caso da Reserva Indígena de Marrecas -PR. 2009. 94f. Dissertação (Mestrado em Desenvolvimento Econômico) - Universidade Federal do Paraná, Curitiba, 2009.

SUDAM-Superintendência do Desenvolvimento da Amazônia. Lei Federal $n^{\circ}$ 5.173, 1996. Legislação sobre a criação da Amazônia Legal. Disponível em: <http://www.sudam.gov.br/amazonia-legal/43-amazonialegallegislacao?format =pdf. $>$ Acesso em: 3 ago. 2012.

SOUZA, C. Políticas Públicas: uma revisão da literatura. Sociologias, Porto Alegre, v. 8, n. 16, jul./dez. 2006. Disponível em: <http://www.scielo.br/pdf/ soc/n16/ a03n16.pdf>. Acesso em: 6 ago. 2012.

SOUSA, R. M. C. de; NAKAJIMA, N. Y.; OLIVEIRA, E. B. de. ICMS ecológico: instrumento de gestão ambiental. Revista Perspectiva, Erechim. v. 35, n. 129, p. 27-43, mar. 2011. Disponível em: < http://www.uricer.edu.br/new/ site/pdfs/ perspectiva/129_152.pdf> Acesso em: 3 ago. 2012.

TOCANTINS. Lei ${ }^{\circ} 1.323$, de 4 de abril de 2002. Dispõe sobre os índices que compõem o cálculo da parcela do produto da arrecadação do ICMS pertencente aos municípios, e adota outras providências. Diário Ofi cial do Estado do Tocantins, n. 1163. Disponível em: <http://sinat.naturatins.to.gov.br/sigie/ controle/inicial/lei.pdf> Acesso em: 2 jul. 2012. 